\title{
Advertising Budget And Sales Paths Under The Dynamics Of The Student Work Control Problem And Regularity Requirements
}

\author{
Aharon Hibshoosh, San Jose State University, USA
}

\begin{abstract}
Consider a firm promoting a product in a fast expanding industry by using advertising as its single promotional tool. The firm's objective is to minimize the overall cost of advertising necessary for reaching certain target sales of the product by the end of a given planning period. We adopt the Student Work Control problem (SWC) framework for modeling this marketing context, in general, and the advertising-sales response function, in particular. We compare the SWC's optimal control budgeting principle with the solutions of equally effective, alternative advertising budgeting principles, which require strong regularity conditions on the path of either the advertising outlays or sales. In contrast to the other principles, SWC's optimal sales path is highly convex to the point that the firm may deliberately accept decreasing sales at the earliest periods. However, its optimal solution requires the firm to advertise in every period and to continue to accelerate its advertising outlays. The resulting Advertising Sales Response function, too, may therefore have a convex section with declining sales, a finding contributing to an optimization-driven explanation of threshold in advertising effect on sales.
\end{abstract}

Keywords: Student Work Control Problem; Advertising Budgeting; Advertising-Sales Response; Regularity Conditions

\section{INTRODUCTION}

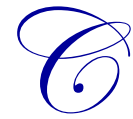

onsider a firm marketing a product in a fast expanding industry in the introduction or the early growth stage of a product life cycle. The firm's objective is reaching a certain level of sales, within a prespecified planning window, in an efficient and regular manner. In general, a firm facing its sales growth dynamics would apply its whole optimal marketing mix. However, in this paper, as is often common in marketing, in modeling sales response to advertising, we treat advertising as the firm's sole decision variable, assuming the role of the rest of the decision variables implicitly. We follow Buratto and Viscolani (1994) in adopting and extending the framework of the Student Work Control problem (SWC) (Raggett, Hempson and Jukes, 1981) for discreetly modeling this marketing context. In particular, we rely on a straightforward extension of the SWC by Klamkin (1985) in flexibly modeling advertising efficiency. For recent continuous extensions of the SWC, see Vornicescu (2009).

Buratto and Viscolani assumed the marketing context of launching a new product where advertising is building goodwill. In contrast, we deal with a product in the introduction or early growth stage, where advertising builds sales, and thus consider different planning implications. Hence, unlike the focus of Buratto and Viscolani on relaxing the assumption of a fixed planning window, our emphasis is on modification and extension of the SWC for the case where the control is restricted not only by the problem's dynamics, but also by regularity conditions on either sales or advertising paths, brought about by abiding by alternative advertising budgeting principles. 
In common with earlier classical approaches to modeling the sales response function to advertising of Nerlove and Arrow (1962), Vidal and Wolfe (1957), the dynamics in the SWC are flexibly representing sales momentum and a decaying of the effect of past sales. However, unlike Nerlove and Arrow, we do not model a case where advertising builds an intervening variable (goodwill) without diminishing returns. In our modeling, the role of intervening variables is subsumed and we assume diminishing return of sales as advertising increases. Neither do we model the case where effectiveness of advertising depends on a market potential as it is modeled by Vidal and Wolfe. When the product is in its growth stage in the product life cycle or is marketed in a fast expanding industry, the evolving product potential is affected by strategic marketing decisions and its assessment is not stable. Hence, in this expository paper, we also chose not to model strategic behavior and, in particular, the pursuit of market share, though we share with Yoo and Mandhachitara (2003) and Miller and Pazgal (2007) the perspective that advertising budgeting principles have material effect on the firm's competitive performance. Instead, we model a credible, but modeling-wise overlooked, objective for a firm in its introductory or early growth stage-a timely attainment of a prescribed sales level. This attainment may be necessary, for example, in order to arrive at required capacity utilization to reach some desired level of market presence or to secure some critical financial support.

In general, for coherent planning, firms are interested in resource employment and sales paths that possess some degree of regularity. The efficiency of reaching any target sales using any advertising control depends on the budgeting principle of the control. The classical list of advertising budgeting principles has been a short one. It typically includes: 1) the Objective and Task principle, a universally tautologically effective and efficient optimal method that is objective-specific, 2) the straight forward and regular, but not necessarily, optimal principles of the Percentage of Sales methods and the Competitive Parity method, and 3) the Affordable Budget method. The comparative parity method tends to be regular because industry practices tend to evolve gradually, but it is not associated with a particular formal regularity condition on the advertising budget that is internal to the firm. The affordable method satisfies feasibility, but not regularity or optimality of the path. With the exception of the percentage of sales methods, the other "textbook" advertising budgeting principles are not inherently based on any internal firm's regularity.

In this paper, we also consider new additional reference principles that embody benchmark regularity in advertising and sales. These regularity conditions require either constant or proportional increments from one period to the next, in either the advertising budget or sales. They are equivalent to requiring a linear temporal path, or alternatively, a geometrically progressing one. Those assumptions are made on either the advertising budget path or on the sales path, but not on both, to avoid contradiction.

Our interest in the effects of regularity conditions is motivated, in part, by recognition that regularity conditions, coupled with the dynamics of advertising-sales relationship, often uniquely determine the optimal advertising control and its related sales path. An insightful result of our study is that requiring a constant rate of growth on the advertising path uniquely (and easily) determines the optimal control of the SWC problem. It is thus identical to the Objective and Task budgeting principle.

The main objective of the paper is to compare the consequences that alternative regularity conditions on the sales path have on the advertising path and vice versa. Applying this inquiry to the characteristic marketing context of this paper, as described by the SWC, would contribute to a sharper advertising budget planning. We are not aware of any study that assumes this line of inquiry, though our study supplements a thorough research stream investigating the role and effect of promotion budgeting by Wagner, Fischer, Albers and Frie in Wagner (2011).

In contrast to the instructive focus of their traditional classification, we view the key differences among the budgeting principles as not primarily rooted in the effectiveness of the principle -"the Goal versus Non-goal Attainment" - but rather in the efficiency of attaining the goal subject to its constraints, particularly 'regularity constraints'.

Actual media budgeting and planning practices motivate and support our perspective. In his UK-based study of multinational firms, Mitchell (1993) has found great discrepancy between the classical list of advertising budgeting principles and the actually applied principles. He reported that, in practice, firms are employing a large number of varied principles which are closely aligned with the marketing purpose of the adverting. 
Yet, in Low and Mohr's (1999) study of the process of setting advertising budgets, the authors observed that the budgeting principles are formed through complex negotiations, through traditional reference to historical precedence of previously employed principles, and to the way of doing business. They concluded that these practices often result in substantial inefficiencies.

Quite often a not-too-overly-complex-or-irregular budgeting principle would be agreed upon. In particular, the finance and accounting parties in the negotiation, for whom regularity in budgeting is a common requirement, are likely to push for budgets with easily decomposable components. Adjustments in accounting and finance are typically comprised of components and procedures which are linear or reflecting constant rates of growth or depreciation. We thus modeled our additional reference budgeting principles accordingly. Finding out whether or how regularity requirements on an advertising path affect the regularity of the sales path or vice versa is clearly of considerable interest.

Following these observations, we took two steps to provide insightful comparison of budgeting principles. First, to facilitate a clearer efficiency comparison, we assume that the sales target is reached by all methods. This requirement was sufficient for the unique determination of an optimal advertising path and a corresponding unique optimal sales path for every budgeting principle compared. In the second step, for every budgeting principle, we derived, where practical, analytical expressions of these optimal solutions. Obtaining explicit path solutions enabled meaningful analytical inquiry of solution properties and eased comparisons and simulations. For instance, we prove that the optimal advertising and sales paths of the Objective and Task principle are strongly convex. However, counter intuitively, perhaps, the sales path need not be monotonic. While the firm is continually increasing its advertising, it may let sales fall for a while before it begins to rise exponentially. In contrast, the optimal advertising and sales paths, based on the Percentage of Sales principles, result in concave sales path pattern that is, as expected, considerably more expensive than that obtained by the Objective and Task method.

The results of this study also supplement the arguments which explain why advertising elasticity is not constant. Previous studies put the focus on the temporal variation of consumer awareness and involvement. Our study complements by implying the joint role of the communicative effect of decaying habitual purchases, consumer experimentation of new products, and the optimality principle of not allocating large advertising outlays when the target is too distant and the profit margin is accelerating rapidly.

\section{PROMOTION-ORIENTED ADAPTATION OF THE SWC}

We model a firm marketing its product in the introduction stage or in the early part of the growth stage of the product's life cycle. As sales expand, the product may move from losses to profits and subsequently its profit and profit margin are highly accelerating. Our base model is essentially a reinterpretation and further analysis of one of several SWC's extensions, proposed in the seminal paper of Raggett, Hempson and Jukes (1981).

We model Sales dynamics discretely. The index $k, k=1, \ldots \mathrm{M}$, denotes the period (day, month, quarter), where $\mathrm{M}$ is the length of the planning period. We denote the sales level at period k as $S_{k}$ and $S_{0}$ is the initial sales level. We assume one control variable, a planned advertisement spending in constant dollars, for period $\mathrm{k}$, denoted as $U_{k}$. The model dynamics is given as:

$S_{k+1}=a S_{k}+b U_{k+1}^{\alpha}$

i.e., the sales level in any current period is a function of sales level in the preceding period and the advertising budget for the current period. On the parameters values, we assume:

$0<a<1$

$b>0$

(C) 2012 The Clute Institute http://www.cluteinstitute.com/ 
These assumptions reflect common assumptions in the consumer behavior and promotion literature in Marketing. Namely, there is imperfect sales inertia whose effect is gradually decaying over time. In addition, next period sales are affected positively by the size of the next period advertising expenditures. This effect on sales exhibits diminishing returns. The model implies that current period advertising has also an indirect positive carryover effect on future sales. However, this effect gradually decays over time.

The assumption of sales decay does not negate fast growth and sales momentum. However, it limits and thus clarifies SWC's range of application. It implies that the overall purchase of the current customer population (rather than that of the individual) must decline from one period to the next when the product price is constant. This is likely to be the case when the product is not frequently consumed. This is common in a wide array of marketing contexts, for example, when the product is a durable good, a shopping good, a special experience, or a special service. Consider, for example, the purchase of new sport exercise equipment, new consumer electronic devices, new airline routes, new types of vacations, new types of financial services, etc. In contrast, if the product is frequently purchased, the learning customer unit may increase rather than decrease its average consumption as its use and satisfaction increase. In this case, our SWC's version does not provide a valid representation of the marketing context.

When the SWC applies, much of the sales momentum may come from the purchase by new customers through product diffusion and adoption that may be directly and indirectly positively affected by the purchases by old consumers via various communication modes. Hence, the expression, $a S_{k}$, would not usually represent the purchase by the old customers in the current period but rather a current purchase that is related to the size of the quantity purchased by the old customers in the preceding period. It includes current purchases of new customers and repeated purchases of old customers. Notice that over time, though, the future purchase of the population's old customers could be higher than their initial purchase through a multiplier effect. Our SWC model applies as long as the current sales induced by past purchases would be smaller than past sales. There are common circumstances where the effect of past purchases alone is so large that sales may accelerate without any advertising. In these cases, our model is not valid.

The lack of universal application of the SWC model is a strength rather than a weakness. It qualifies the effect of advertising and provides a balanced view of promotion. Much of the growth in the next period may be a result of the effect of past purchases rather than due to current advertising. Furthermore, we do not assume that advertising is responsible for the initial sales level. Many small enterprises cannot originally afford advertising expense and their sales are initially built up by other promotional means. However, they often may turn to advertising once some minimal sales level is reached in order to accelerate sales. Advertising is thus needed to support sales expansion, though it may or may not be the main force behind this expansion. As a result of the functioning of the advertising, it may be the increasing extent of customers' experiences with the product that keeps propelling the product's sales higher.

The specific functional form of the dynamics has some attractive parsimonious conceptual and measurement properties. The rate of decay, $a$, in the effect of current sales on next period's sales is fixed. Thus, Sales are conceptually conceived as the "depreciating capital" of the firm reflecting modern marketing focus on customers' equity and retention. The amount of the efficiency units of the advertising budget is $U^{\alpha}$. The parameter, $b$, provides a direct measure of the effect of an efficiency unit of the advertising budget (i.e., a unit of $U^{\alpha}$ ) on sales. The parameter $\alpha$, as a fraction, represents the diminishing return of advertising effect on current sales. Specifically, we assume that the net current sales increment, not explained by past sales purchases, is a constant elasticity function of current advertising budget outlay. This implies that advertising elasticity varies over time with regularity as the product life cycle evolves and advertising expenditures change-a widely empirically supported phenomena (see Sethuraman, Tellis, and Briesch, 2011). 
We further assume that the marketer's firm has the goal of achieving a target sales level $S^{M}=S_{M}$ by the end of the of the Mth period, with the obvious restriction of reaching higher sales, $S^{M}>S_{0}$. The planner's objective is to minimize the total advertising cost (in constant dollars) for the whole planning period, $U=\sum_{1}^{M} U_{i}$. Formally the problem can be summarized as

$\operatorname{Min} U=\sum_{1}^{M} U_{i}$

subject to $S_{k+1}=a S_{k}+b U_{k+1}^{\alpha}$

with $0<a<1, b>0$ and $0<\alpha<1$.

The key feature of our model adaptation is the assumption of sales as a state variable whose level is ultimately affected by advertising. Planners commonly perceive the ultimate goal of advertising as sales increase. Advertising usually affects an only partially observable complex communication process, with many interrelated intervening variables, which eventually affects sales, although, on occasion, the mere act of advertising may directly affect sales. Advertising is often used to increase levels of awareness, product familiarity, customer involvement, favorable attitude, etc. The level of measurement of these intervening variables is at most ordinal and their measurement requires dedicated study. We chose to subsume this complex and varied process in order to arrive at a parsimonious model that focuses on the relationships between the observable variables of advertising budgets and sales. Moreover, marketing scholars have had interest in the inverse direction, as well - that of sales affecting advertising expenditures. Our interpretation of the SWC, as a sales-advertising model, allows straight forward extension and convenient inquiry in this direction.

\section{ANALYSIS AND SIMULATION OF ADVERTISING AND SALES PATHS}

\section{Optimal Solution of the Base SWC under the Objective and Task Budgeting Principle}

In this section, we present optimal explicit parametric solutions of the advertising budget path, the corresponding optimal sales path, and the corresponding expression for the optimal total advertising cost. We do it first for the original problem (5) where no additional regularity constraints are added. This forms our base model. We naturally refer to the optimal solution of this problem as the Objective and Task solution.

Without additional regularity constraints, the optimal solution for (5) is proven in Klamkin (1985) in elementary fashion based on geometrical features and Holder's inequalities. He focuses on the key feature of the optimal solution; namely, that the control path (the advertising path in our case) is geometrically progressing and on evaluation and comparison of the overall time cost with that obtained under uniform control. Klamkin was not concerned with deriving explicit expression of the features of the optimal path of the objective in terms of the parameters of the model. Focusing on identifying the distinguishing features of both the advertising and sale paths, we have supplemented his work. We derive explicit, non-recursive solutions for both paths.

Klamkin derives the optimal control solution (our advertising budget), as follows:

$U_{i}=\frac{\lambda}{a^{\frac{i}{(1-\alpha)}}}$, where $\lambda$ is a coefficient which is optimally computed.

This form clearly demonstrates a geometric progression of the advertising path. 
For simplification of exposition and derivation, we may write (6) as

$$
U_{i}=\frac{\lambda}{\left[a^{\frac{1}{2(1-\alpha)}}\right]^{2 i}}=\frac{\lambda}{a^{\wedge^{2 i}}}
$$

where

$$
a^{\wedge}=a^{\frac{1}{2(1-\alpha)}}=\frac{1}{r}
$$

Hence, we can express (7) as

$$
U_{i}=\frac{\lambda}{\left[a^{\frac{1}{2(1-\alpha)}}\right]^{2 i}}=\frac{\lambda}{a^{\wedge i}}=\lambda r^{2 i}=\lambda\left(r^{2}\right)^{i}
$$

The expression of $S_{k}$, the sales function at period $\mathrm{k}$, in terms of the parameters of the models and the optimal advertising budget, is obtained recursively by considering the dynamics (1) and substituting the $U_{i} \mathrm{~s}$, the past advertising budgets values, as follows:

$$
S_{1}=a S_{0}+\lambda b r^{2}
$$

$S_{2}=a S_{1}+b\left(\lambda r^{2}\right)^{2}=a^{2} S_{0}+\lambda a b r^{2}+\lambda b r^{4}$

$$
S_{3}=a S_{2}+b\left(\lambda r^{2}\right)^{2}=a^{3} S_{0}+\lambda a^{2} b r^{2}+\lambda a b r^{4}+\lambda b r^{6}
$$

In general,

$$
S_{k}=a^{k} S_{0}+b \lambda\left[a^{k-1}\left(r^{2}\right)^{1}+a^{k-2}\left(r^{2}\right)^{2}+\ldots+a^{0}\left(r^{2}\right)^{k}\right]=a^{k} S_{0}+b \lambda \sum_{i=1}^{k} a^{i}\left(r^{2}\right)^{k-i}
$$

This expression is quite complex, yet its decomposition into two terms is insightful. The first term in (11) is the decaying habitual effect of the initial sales on current sales. The second convolution-like expression represents the effect of the advertising stream in the planning period, up to and including the one in the given current period. Within this complex expression, the gradual transition in the effects of the initial parameters as k increases, indicates a regular sales path.

To complete the explicit expression of $S_{k}$ in terms of the initial parameters of the model, we need to strictly express $\lambda$ in terms of those parameters. Notice that 


$$
\begin{aligned}
& \frac{S^{M}-a^{M} S_{0}}{b a^{M}}=\left(\frac{U_{1}^{\alpha}}{a}+\frac{U_{2}^{\alpha}}{a^{2}}+\ldots+\frac{U_{M}^{\alpha}}{a^{M}}\right)=\lambda^{\alpha}\left(\frac{1}{a^{\frac{1}{1-\alpha}}}+\frac{1}{a^{2 \frac{1}{1-\alpha}}}+\ldots+\frac{1}{a^{M \frac{1}{1-\alpha}}}\right) \\
& =\lambda^{\alpha} \frac{1}{a^{\frac{1}{1-\alpha}}} \frac{\left[1-\left(\frac{1}{a}\right)^{\frac{M}{1-\alpha}}\right]}{\left[1-\left(\frac{1}{a}\right)^{\frac{1}{1-\alpha}}\right]}=\lambda^{\alpha} \frac{\left[1-a^{\frac{M}{1-\alpha}}\right]}{\left[1-a^{\frac{1}{1-\alpha}}\right] a^{\frac{M}{1-\alpha}}}
\end{aligned}
$$

We thus obtain the expression

$$
\lambda=\left\{\frac{S^{M}-a^{M} S_{0}}{b a^{M}} \frac{\left[1-a^{\frac{1}{1-\alpha}}\right] a^{\frac{M}{1-\alpha}}}{\left[1-a^{\frac{M}{1-\alpha}}\right]}\right\}^{\frac{1}{\alpha}}=\left\{\frac{S^{M}-a^{M} S_{0}}{b} \frac{\left[1-a^{\frac{1}{1-\alpha}}\right] a^{\frac{M \alpha}{1-\alpha}}}{\left[1-a^{\frac{M}{1-\alpha}}\right]}\right\}^{\frac{1}{\alpha}}
$$

which can be substituted in (11) to obtain the explicit expression for $S_{k}$.

Similarly, we can express the Advertising budget at period k, in terms of the initial parameters, as

$$
U_{k}=\frac{\lambda}{a^{\frac{k}{1-\alpha}}}=\frac{1}{a^{\frac{k}{1-\alpha}}}\left\{\frac{S^{M}-a^{M} S_{0}}{b a^{M}} \frac{\left[1-a^{\frac{1}{1-\alpha}}\right] a^{\frac{M}{1-\alpha}}}{\left[1-a^{\frac{M}{1-\alpha}}\right]}\right\}^{\frac{1}{\alpha}}
$$

Hence, as shown by Kalamkin and interpreted by Buratto and Viscolani, the optimal $U_{i}$ s are forming a geometric queue and the corresponding optimal total advertising budget, in terms of the initial parameters of the model, is

$U_{\text {Min }}=\left\{\frac{S^{M}-a^{M} S_{0}}{b}\left[\frac{1-a^{\frac{1}{(1-\alpha)}}}{1-a^{\frac{M}{(1-\alpha)}}}\right]^{1-\alpha}\right\}^{\frac{1}{\alpha}}$

In the rest of this section, we develop optimal solutions and compare efficiencies of alternative budgeting principles. To make pure efficiency comparisons, we assume that the objective is reached by every principle in every case.

\section{Solutions for the Percentage of Sales principles}

\section{Advertising Budget Proportional To The Preceding Period Sale}

In this case, we consider first the case where the advertising budget affecting the current period is set as some fixed fraction of the preceding period. As will be shown below, applying the fixed fraction to the current period sales leads to similar insights.

In contrast with the common treatment where this fixed proportion is handled as some exogenous variable without regard to meeting the firm's pre-specified objective, we are assuming here that the fixed percentage was optimally chosen to attain the pre-specified sales level, $S^{M}$, at the end of the planning period. Substituting advertising in (1), as a percentage of preceding period sales, the dynamics become 


$$
S_{k+1}=a S_{k}+b\left(c S_{k}\right)^{\alpha}=a S_{k}+b c^{\alpha} S_{k}^{\alpha}
$$

Using forward recursions, it is possible to develop explicit parametric solutions of $S_{k}$ as follows:

$$
\begin{aligned}
& S_{1}=a S_{0}+b c^{\alpha} S_{0} \\
& S_{2}=a S_{1}+b c^{\alpha} S_{1}^{\alpha}=a\left(a S_{0}+b c^{\alpha} S_{0}^{\alpha}\right)+b c^{\alpha}\left(a S_{0}+b c^{\alpha} S_{0}^{\alpha}\right)^{\alpha} \\
& =a^{2} S_{0}+a b c^{\alpha} S_{0}^{\alpha}+b c^{\alpha}\left(a S_{0}+b c^{\alpha} S_{0}^{\alpha}\right)^{\alpha} \\
& S_{3}=a S_{2}+b c^{\alpha} S_{2}^{\alpha} \\
& =a^{3} S_{0}+a^{2} b c^{\alpha} S_{0}^{\alpha}+a b c^{\alpha}\left(a S_{0}+b c^{\alpha} S_{0}^{\alpha}\right)^{\alpha}+b c^{\alpha}\left[a^{2} S_{0}+a b c^{\alpha} S_{0}^{\alpha}+b c^{\alpha}\left(a S_{0}+b c^{\alpha} S_{0}^{\alpha}\right)^{\alpha}\right]^{\alpha}
\end{aligned}
$$

Hence, it is possible to obtain a non-recursive expression of $S_{k}$ in terms of the initial parameters of the model via forward recursion. Yet, it is easy to see that this expression of the sales in terms of the model's parameters is extremely complex, to the point that deriving a non-recursive expression for $S_{k}$ is not merited. Instead, the simplest expression is the recursive relationship between $S_{k}$ and $S_{k-1}(16)$. This is further clarified by the fact that working recursively backward from $S_{M}$ is hopeless because no general explicit algebraic solution for $S_{k-1}$, in terms of a given $S_{k}$, can be derived from the difference equation (16).

It should be noted that for $\alpha=0.5$, it is possible to obtain some explicit solution for $S_{k-1}$ as (16) is expressible, in this case, as a quadratic equation in $S_{k}^{0.5}$. While explicit solutions for every k can thus be obtained recursively in this case, their expression clearly becomes too quickly too complex to be of value in further analysis.

Consequently, in the Percentage of Sales criteria, it is much easier to find the solution, even in the simplest case, by direct numerical search for the suitable proportion coefficient that will bring sales from $S_{0}$ to $S_{M}$ in M periods. A higher parameter $c$ means that a higher percentage of sales is allocated to advertising. This, in turn, means that the sales level in every period is strictly higher, but both advertising and current sales are a continuous function in $c$. Hence, the accumulated sales level at any period is continuous and monotonic in $c$ as an additive superposition of continuous monotonic functions in $c$. Hence, the optimal level of $c$ can be found easily by a simple search while simultaneously direct numerical and graphical representation of the sales path and the advertising path are discovered.

\section{Advertising Budget Proportional To Current Period Sales}

In this case, denoting the ratio of advertising budget to sales as $c$, we can write (1) as

$$
S_{k+1}=a S_{k}+b\left(c S_{k+1}\right)^{\alpha}
$$

or

$$
S_{k}=\frac{1}{a}\left(S_{k+1}-b c^{\alpha} S_{k+1}^{\alpha}\right)
$$


We can thus obtain by backward recursion

$$
\begin{aligned}
& S_{M}=S^{M} \\
& S_{M-1}=\frac{1}{a}\left(S^{M}-b c^{\alpha} S^{M \alpha}\right) \\
& S_{M-2}=\frac{1}{a}\left(S_{M-1}-b c^{\alpha} S_{M-1}^{\alpha}\right)=\frac{1}{a}\left[\frac{1}{a}\left(S^{M}-b c^{\alpha} S^{M \alpha}\right)-b c^{\alpha} \frac{1}{a}\left(S^{M}-b c^{\alpha} S^{M \alpha}\right)^{\alpha}\right]
\end{aligned}
$$

and so on. As in the case where the proportion is a fraction of last period's sale, the explicit formulae are derivable but are too complex to be of value. Similarly, obtaining an expression by forward recursion is, in general, hopeless as there is no general explicit solution for $S_{k+1}$ in the difference in equation (19). However, backward recursive computation of sales is quite simple. Similarly, search-based numerical determination of the optimal percentage can be employed and computing the corresponding sales and advertising budget paths is easy. Because of the similarity of the two Percentage of Sales methods, we consider below only the one based on percentage of the preceding period's sales when making comparison with other principles.

In addition to the above two classical advertising budgeting principles, we are considering other methods for determination of advertising budgets that manifest regularity of either the advertising path or the sales path.

In the case of regular advertising paths, we consider three patterns: 1) A constant advertising budget, 2) A linear advertising budget initiating from the origin (or equivalently, a fixed periodical increment in the advertising budget), and 3) A fixed proportional increase in the periodic advertising budget (or equivalently, an advertising budget that exhibits a fixed periodic growth rate). As we have shown above, Case 3 turned out to be equivalent to the Objective and Task method, as the latter results in a geometrically progressed solution. Hence, we need to analyze only cases 1 and 2 .

Similarly, in the case of regular sales paths, we consider two patterns: 1) A linear sales increase and 2) A sales path with a fixed growth rate.

\section{Solution for the Constant Advertising Budget Principle}

The corresponding value for a uniform advertising policy with a constant $\bar{U}$ advertising budget in each period is obtained as follows:

$$
\begin{aligned}
& S_{1}=a S_{0}+b \bar{U}_{\text {const }}^{\alpha} \\
& S_{2}=a S_{1}+b \bar{U}_{\text {const }}^{\alpha}=a\left(a S_{0}+b \bar{U}_{\text {const }}^{\alpha}\right)+b \bar{U}_{\text {const }}^{\alpha}=a^{2} S_{0}+a b \bar{U}_{\text {const }}^{\alpha}+b \bar{U}_{\text {const }}^{\alpha} \\
& S_{3}=a S_{2}+b \bar{U}_{\text {const }}^{\alpha} \\
& =a\left(a^{2} S_{0}+a b \bar{U}_{\text {const }}^{\alpha}+b \bar{U}_{\text {const }}^{\alpha}\right)+b \bar{U}_{\text {const }}^{\alpha}=a^{3} S_{0}+a^{2} b \bar{U}_{\text {const }}^{\alpha}+a b \bar{U}_{\text {const }}^{\alpha}+b \bar{U}_{\text {const }}^{\alpha}
\end{aligned}
$$

In general, an explicit solution for the Sales path is thus obtained as

$$
S_{k}=a^{k} S_{0}+a^{k-1} b \bar{U}_{\text {const }}^{\alpha}+\ldots+a b \bar{U}_{\text {const }}^{\alpha}+b \bar{U}_{\text {const }}^{\alpha}=a^{k} S_{0}+b \bar{U}_{\text {const }}^{\alpha} \sum_{i=0}^{k-1} a^{i}=a^{k} S_{0}+b \bar{U}_{\text {const }}^{\alpha} \frac{1-a^{M}}{1-a}
$$


Also, in particular for the Mth period, from (22) it follows that

$$
\frac{S^{M}-a^{M} S_{0}}{b a^{M}}=\frac{\bar{U}_{\text {const }}^{\alpha}}{a}+\frac{\bar{U}_{c o n s t}^{\alpha}}{a^{2}}+\ldots+\frac{\bar{U}_{c o n s t}^{\alpha}}{a^{M}}=\bar{U}_{\text {const }}^{\alpha} \frac{\left[1-\left(\frac{1}{a}\right)^{M}\right]}{a\left(1-\frac{1}{a}\right)}=\bar{U}_{\text {const }}^{\alpha} \frac{1-a^{M}}{(1-a) a^{M}}
$$

Hence, every period's advertising budget is

$$
\bar{U}_{\text {const }}=\left(\frac{S^{M}-a^{M} S_{0}}{b} \frac{1-a}{1-a^{M}}\right)^{\frac{1}{\alpha}}
$$

and the total advertising budget for the whole planning horizon is

$$
U_{\text {const }}=M\left(\frac{S^{M}-a^{M} S_{0}}{b} \frac{1-a}{1-a^{M}}\right)^{\frac{1}{\alpha}}
$$

\section{Solution for the Linear Advertising Budget Principle}

In this case, we label $\bar{U}_{i n c}$ as the constant periodic increment in the advertising budget. We obtain

$$
S_{1}=a S_{0}+b \bar{U}_{i n c}^{\alpha}
$$

$$
\left.S_{2}=a S_{1}+b 2^{\alpha} \bar{U}_{i n c}^{\alpha}\right)=a\left(a S_{0}+b \bar{U}_{i n c}^{\alpha}\right)+b 2^{\alpha} \bar{U}_{i n c}^{\alpha}=a^{2} S_{0}+a b \bar{U}_{i n c}^{\alpha}+b 2^{\alpha} \bar{U}_{i n c}^{\alpha}
$$$$
S_{3}=a S_{2}+b \bar{U}_{i n c}^{\alpha}=a\left(a^{2} S_{0}+a b \bar{U}_{i n c}^{\alpha}+b 2^{\alpha} \bar{U}_{i n c}^{\alpha}\right)+b 3 \bar{U}_{i n c}^{\alpha}=a^{3} S_{0}+a^{2} b \bar{U}_{i n c}^{\alpha}+a b 2^{\alpha} \bar{U}_{i n c}^{\alpha}+b 3^{\alpha} \bar{U}_{i n c}^{\alpha}
$$

In general,

$$
S_{k}=a^{k} S_{0}+a^{k-1} b \bar{U}_{i n c}^{\alpha}+\ldots+a b(k-1)^{\alpha} \bar{U}_{i n c}^{\alpha}+b k^{\alpha} \bar{U}_{i n c}^{\alpha}=a^{k} S_{0}+b \bar{U}_{i n c}^{\alpha} \sum_{i=0}^{k-1} a^{i}(k-i)^{\alpha}
$$

In particular, for $S_{M}=S^{M}$, we obtain

$$
S^{M}-a^{M} S_{0}=b \bar{U}_{i n c}^{\alpha} \sum_{i=0}^{M-1} a^{i}(M-i)^{\alpha}
$$

and the optimal

$$
\bar{U}_{i n c}=\left[\frac{S^{M}-a^{M} S_{0}}{b \sum_{i=0}^{M-1} a^{i}(M-i)^{\alpha}}\right]^{\frac{1}{\alpha}} \text {. }
$$

Next, we obtain the explicit expression of the sales at period k by substitution of (29) in (27). This formula describes current sales as comprised of two additive components. The first element is the decaying habitual initial sales. In the second element, we observe a sales gap that only sales generated by advertising in the planned period 
could and must fill. This sales gap is getting gradually filled and the second component in the second expression is the cumulative portion of the gap filled by the kth period.

$$
S_{k}=a^{k} S_{0}+\left(S^{M}-a^{M} S_{0}\right) \frac{\sum_{i=0}^{k-1} a^{i}(k-i)^{\alpha}}{\sum_{i=0}^{M-1} a^{i}(M-i)^{\alpha}}
$$

The corresponding optimal advertising path is obtained simply as

$$
U_{i}=k \bar{U}_{i n c}=k\left[\frac{S^{M}-a^{M} S_{0}}{b \sum_{i=0}^{M-1} a^{i}(M-i)^{\alpha}}\right]^{\frac{1}{\alpha}}
$$

and the optimal advertising cost is

$$
U_{a d v-L i n}=\bar{U}_{i n c} \frac{(M+1) M}{2}
$$

Next, we analyze two new principles with regularity conditions on the sales path.

\section{Solution for the Linear Sales Principle}

We are considering linear sales path originating at $S_{0}$. Since the initial and final sales are parameters of the SWC model, a linear sales path implies a constant sales increment in each period. Dividing the planning period's sales growth into identical periodical sales increments results in a periodic increment of

$$
\left(\frac{S^{M}-S_{0}}{M}\right)
$$

An explicit representation of the sales level in terms of the model parameters is

$$
S_{k}=S_{0}+\frac{k\left(S^{M}-S_{0}\right)}{M}
$$

This period $\mathrm{k}$ sales increment has to be generated by the period $\mathrm{k}$ advertising budget and the preceding period sales, according to model's dynamics (1). Specifically,

$$
S_{0}+(k+1) \frac{S^{M}-S_{0}}{M}=a\left(S_{0}+k \frac{S^{M}-S_{0}}{M}\right)+b U_{k+1}^{\alpha}
$$

We obtain, the optimal advertising path as

$$
U_{k+1}=\left\{\frac{1}{b}\left\{(1-a) S_{0}+[(k(1-a)+1)] \frac{S^{M}-S_{0}}{M}\right\}\right\}^{\frac{1}{\alpha}}
$$


Hence, $U_{k}^{\alpha}$ is linear in k-1 and thus in $\mathrm{k} . U_{k}$ is a polynomial in $\mathrm{k}$ and it is clearly an increasing function in $\mathrm{k}$ because $a<1$ and $0<\alpha<1$.

The minimum total advertising cost is

$\left.U_{\text {SalesLin }}=\sum_{i=1}^{k}\left\{\frac{1}{b}\left\{(1-a) S_{0}+[(i-1)(1-a)+1)\right] \frac{S^{M}-S_{0}}{M}\right\}\right\}^{\frac{1}{\alpha}}$ computable.

Both the period's advertising budget and the total cost thus have complex explicit solutions that are easily

\section{Solution for the Proportional Sales Growth Principle}

In this case, current sales are proportional to the preceding period sales with a proportion coefficient $c$. Hence, substituting $S_{k+1}=c S_{k}$ in (1)

we obtain

$c S_{k}=a S_{k}+b U_{k+1}^{\alpha}$

Hence,

$U_{k+1}=\left[\frac{(c-a)}{b} S_{k}\right]^{\frac{1}{\alpha}}$

It follows that the current advertising budget is a constant elasticity function of the preceding period's sales. Under a proportional sales path, sales grow geometrically.

$S^{k}=c^{k} S_{0}$

Since the firm's objective is reaching the target sales level of $S^{M}$ by the end of the planning window, we obtain, in particular:

$S^{M}=c^{M} S_{0}$

Hence, we obtain the optimal proportion

$c=\left(\frac{S_{M}}{S_{0}}\right)^{\frac{1}{M}}$

and the optimal rate of sales growth is

$c-1=\left(\frac{S_{M}}{S_{0}}\right)^{\frac{1}{M}}-1$

Substitution of (42) in (40) provides us with the explicit optimal Sales level formula.

Similarly, by substituting the optimal value of $c$ from (42) in (39), we obtain the explicit expression for the optimal advertising quarterly budget in terms of the model's parameter. 


$$
U_{k}=\left[\frac{c-a}{b} c^{k-1} S_{0}\right]^{\frac{1}{\alpha}}=\left[\frac{c^{k}-a c^{k-1}}{b} S_{0}\right]^{\frac{1}{\alpha}}
$$

and the minimum total advertising cost is

$$
U_{\text {Propsales }}=S_{0}^{\frac{1}{\alpha}} \sum_{k=1}^{M}\left[\frac{c^{k}-a c^{k-1}}{b}\right]^{\frac{1}{\alpha}}
$$

\section{Simulation}

In Table 1, we present simulation of the six principles for budgeting advertising applied in the case where the parameters are $a=0.8, b=3$ and $\alpha=0.5$. The objective is to raise sales from $S_{0}=1$ to $S_{M}=10$. We have already established that the Objective and Task method is identical to the optimal Proportional Advertising method. Overall, this principle is the optimal one, resulting in an advertising budget of 3.99. It is followed by the Proportional Sales principle (4.41), by the Linear Sales principle (5.63), and the Linear Advertising principle (5.99). Applying Percentage of Sales Principle results is next (6.42). The worst performing principle is the Constant Advertising budget one (9.08).

\begin{tabular}{|c|c|c|c|c|c|c|c|c|c|c|c|c|}
\hline \multirow{2}{*}{$\begin{array}{l}\text { Model } \\
\text { Period }\end{array}$} & \multicolumn{2}{|c|}{$\begin{array}{c}\text { 1. Objective and } \\
\text { Task }\end{array}$} & \multicolumn{2}{|c|}{$\begin{array}{c}\text { 2. Percentage of } \\
\text { Sales }\end{array}$} & \multicolumn{2}{|c|}{$\begin{array}{l}\text { 3. Constant } \\
\text { Adv. }\end{array}$} & \multicolumn{2}{|c|}{$\begin{array}{l}\text { 4. Linear } \\
\text { Adv. }\end{array}$} & \multicolumn{2}{|c|}{$\begin{array}{l}\text { 5. Linear } \\
\text { Sales }\end{array}$} & \multicolumn{2}{|c|}{$\begin{array}{c}\text { 6. Proportional } \\
\text { Sales }\end{array}$} \\
\hline & $\begin{array}{c}\text { Adv. } \\
\text { Budget }\end{array}$ & Sales & $\begin{array}{c}\text { Adv. } \\
\text { Budget }\end{array}$ & Sales & $\begin{array}{c}\text { Adv. } \\
\text { Budget }\end{array}$ & Sales & $\begin{array}{c}\text { Adv. } \\
\text { Budget }\end{array}$ & Sales & $\begin{array}{c}\text { Adv. } \\
\text { Budget }\end{array}$ & Sales & $\begin{array}{c}\text { Adv. } \\
\text { Budget }\end{array}$ & Sales \\
\hline 1 & 0.0003 & 0.8518 & 0.054 & 1.497 & 0.4539 & 2.821 & 0.0285 & 1.307 & 0.0469 & 1.45 & 0.0115 & 1.122 \\
\hline 2 & 0.00047 & 0.7462 & 0.0808 & 2.050 & 0.4539 & 4.278 & 0.0571 & 1.762 & 0.0608 & 1.90 & 0.0145 & 1.259 \\
\hline 3 & 0.00073 & 0.678 & 0.1106 & 2.638 & 0.4539 & 5.444 & 0.0856 & 2.287 & 0.0765 & 2.35 & 0.0183 & 1.413 \\
\hline 4 & 0.00114 & 0.6436 & 0.1423 & 3.242 & 0.4539 & 6.376 & 0.1141 & 2.843 & 0.094 & 2.80 & 0.023 & 1.585 \\
\hline 5 & 0.00178 & 0.6414 & 0.1749 & 3.848 & 0.4539 & 7.122 & 0.1426 & 3.407 & 0.1133 & 3.25 & 0.0289 & 1.778 \\
\hline 6 & 0.00278 & 0.6713 & 0.2076 & 4.445 & 0.4539 & 7.719 & 0.1712 & 3.967 & 0.1344 & 3.70 & 0.0364 & 1.995 \\
\hline 7 & 0.00434 & 0.7347 & 0.2398 & 5.025 & 0.4539 & 8.196 & 0.1997 & 4.514 & 0.1573 & 4.15 & 0.0459 & 2.239 \\
\hline 8 & 0.00679 & 0.8349 & 0.2711 & 5.582 & 0.4539 & 8.578 & 0.2282 & 5.044 & 0.182 & 4.60 & 0.0577 & 2.512 \\
\hline 9 & 0.0106 & 0.9768 & 0.3012 & 6.112 & 0.4539 & 8.884 & 0.2567 & 5.556 & 0.2085 & 5.05 & 0.0727 & 2.818 \\
\hline 10 & 0.01657 & 1.1676 & 0.3298 & 6.613 & 0.4539 & 9.128 & 0.2853 & 6.047 & 0.2368 & 5.50 & 0.0915 & 3.162 \\
\hline 11 & 0.02588 & 1.4167 & 0.3567 & 7.082 & 0.4539 & 9.324 & 0.3138 & 6.518 & 0.2669 & 5.95 & 0.1152 & 3.548 \\
\hline 12 & 0.04044 & 1.7367 & 0.3821 & 7.520 & 0.4539 & 9.480 & 0.3423 & 6.969 & 0.2988 & 6.40 & 0.1451 & 3.981 \\
\hline 13 & 0.06319 & 2.1435 & 0.4057 & 7.927 & 0.4539 & 9.605 & 0.3708 & 7.402 & 0.3325 & 6.85 & 0.1826 & 4.467 \\
\hline 14 & 0.09874 & 2.6575 & 0.4276 & 8.303 & 0.4539 & 9.705 & 0.3994 & 7.818 & 0.368 & 7.30 & 0.2299 & 5.012 \\
\hline 15 & 0.15428 & 3.3044 & 0.448 & 8.650 & 0.4539 & 9.785 & 0.4279 & 8.217 & 0.4053 & 7.75 & 0.2894 & 5.624 \\
\hline 16 & 0.24107 & 4.1164 & 0.4667 & 8.970 & 0.4539 & 9.850 & 0.4564 & 8.600 & 0.4444 & 8.20 & 0.3644 & 6.310 \\
\hline 17 & 0.37667 & 5.1344 & 0.4839 & 9.263 & 0.4539 & 9.901 & 0.4849 & 8.969 & 0.4853 & 8.65 & 0.4587 & 7.080 \\
\hline 18 & 0.58854 & 6.409 & 0.4997 & 9.531 & 0.4539 & 9.942 & 0.5135 & 9.325 & 0.528 & 9.10 & 0.5775 & 7.943 \\
\hline 19 & 0.91959 & 8.004 & 0.5142 & 9.776 & 0.4539 & 9.975 & 0.542 & 9.669 & 0.5725 & 9.55 & 0.727 & 8.913 \\
\hline 20 & 1.43687 & 9.999 & 0.5274 & 10.00 & 0.4539 & 10.00 & 0.5705 & 10.00 & 0.6188 & 10.00 & 0.9153 & 10.00 \\
\hline $\begin{array}{l}\text { Total } \\
\text { Budget }\end{array}$ & 3.99 & & 6.42 & & 9.08 & & 5.99 & & 5.63 & & 4.41 & \\
\hline
\end{tabular}

Table 1: Advertising Outlays and Sales Under Alternative Budget Principles*

* For: $a=0.8, b=3, \alpha=\frac{1}{2}, \mathrm{M}=20, S_{0}=1$ and $S_{M}=20$

Let us compare the paths of the alternative optimal solutions. Since the order of magnitude of the advertising budget and sales are different, we make the comparison in two separate graphs. In Figure 1, we compare the advertising paths for different advertising budgeting principles and in Figure 2, we compare the respective sales paths. 


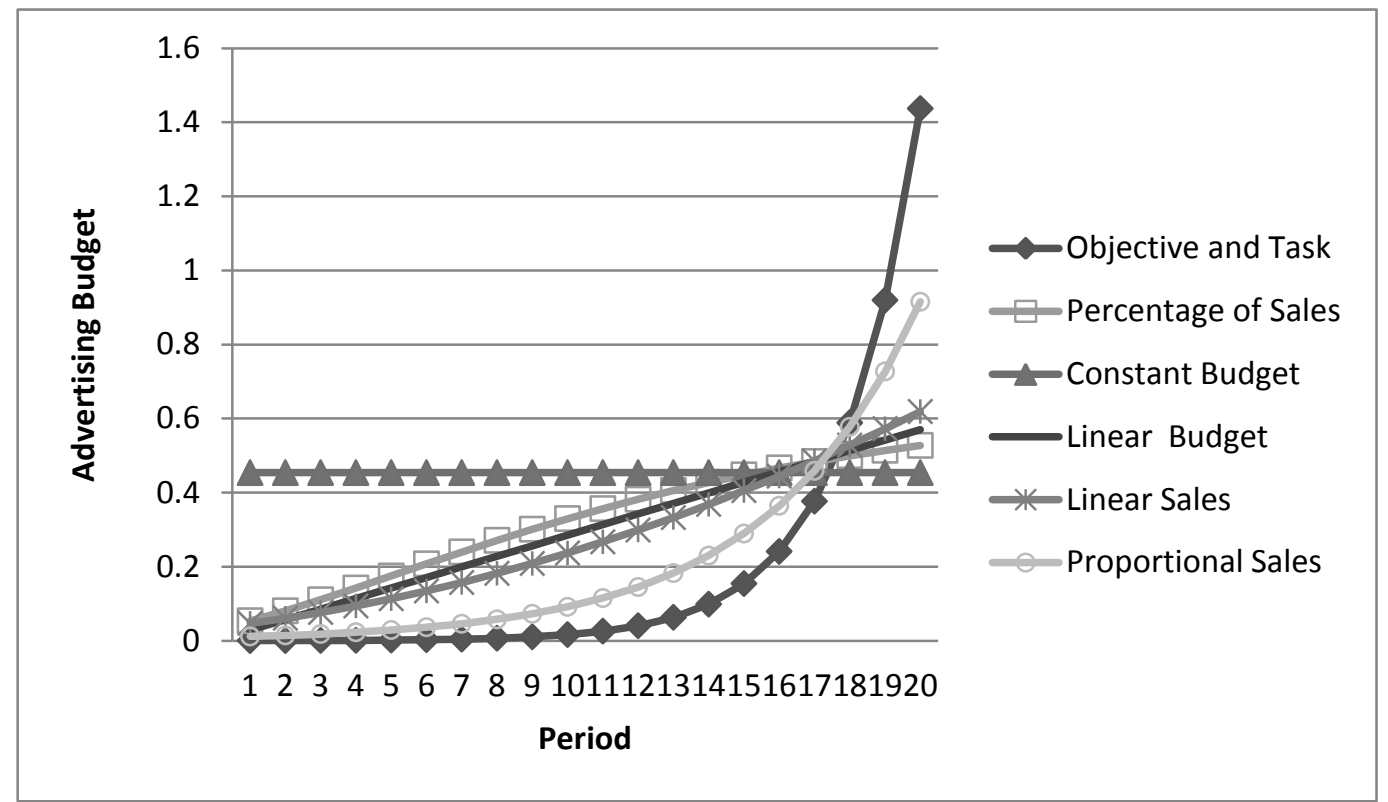

Figure 1: Advertising Budget Paths Under Alternative Advertising Budget Principles

Figure 1 demonstrates that regardless of the budgeting principle, the advertising outlays are strictly monotonically increasing, except, of course, in the case of a constant advertising expenditures. Also, with the possible exception of the Constant Advertising principle, among the compared paths, the greater the convexity of the advertising budget, the greater is its relative advantage. Up to the limit set by the Objective and Task solution, as an envelope function, improving the convexity improves advertising efficiency. The Objective and Task principle and the Proportional Sales principles result in highly convex advertising schedules. The path of the Linear Sales principle is slightly convex and that of the Percentage of Sales is slightly concave. The constant advertising budget is the only principle whose budget does not begin at very low levels of advertising. Notice that the quarterly advertising outlays of the convex budgeting methods exceed the non-convex ones only in the last three periods.

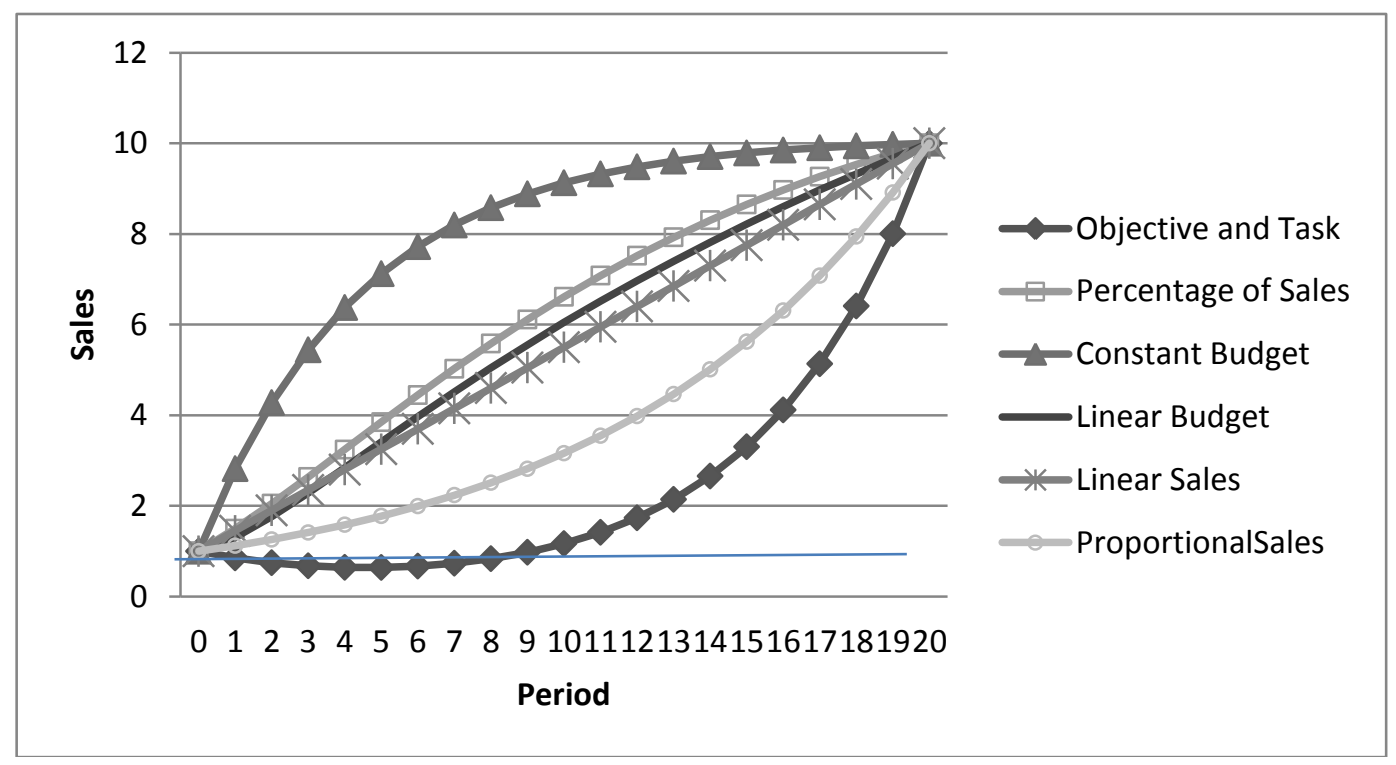

Figure 2: Sales Paths Under Alternative Advertising Budget Principles 
Figure 2, presenting the sales paths, shows almost uniformly strict sales order that corresponds to the optimality order of the principles. The only exception is that sales based on Linear Advertising are slightly lower than those based on Linear Sales in the first three periods. Otherwise, the sales paths of every principle never intersect and a principle whose sales path is more convex than another corresponds to a lesser total advertising budget. We can conclude that a higher efficiency in reaching the target is obtained by greater postponement of the advertising effort to the more distant period. Among the compared principles, the more accelerated the growth in the sales path at the end of the planning period, the more efficient it is in attaining the target. Like in the case of advertising path, the Objective and Task sets the limit on this convexity.

\section{THE OPTIMAL OBJECTIVE AND TASK SOLUTION}

A close examination of Figure 2 and Table 1 shows that unlike advertising outlays, sales are not necessarily monotonically increasing, even in the broad sense. Moreover, this exception is important as it applies in the case of the optimal Objective and Task method. In the first five quarters, its sales are declining and only then turn around and increase. This indicates that the initial advertising outlays have important noticeable downside. Their impact, as part of sales increment, is mostly eradicated over time. Their low level and the associated sales decrease is justified by the need to maximize efficiency in reaching the ultimate sales goal. This need places the focus on accelerating advertising in the end part of the planning period. Nonetheless, it remains optimal to advertise during the whole planning period. So, under the objective of the SWC and its dynamics, some advertising is always preferred over no advertising. In particular, advertising pulsing policies, not considered in this paper, must be inferior to the Objective and Task solution in this market context.

Consequently, the optimal market response function, of the Objective and Task solution, is qualitatively different than the traditional ones that exhibit either an S Shape or a convex shape, where sales are always increasing as advertising budget increases. The Sales response function first increases and then decreases as advertisement budgets are optimally increase. Figures 3 and 4 represent the market response function for this case.

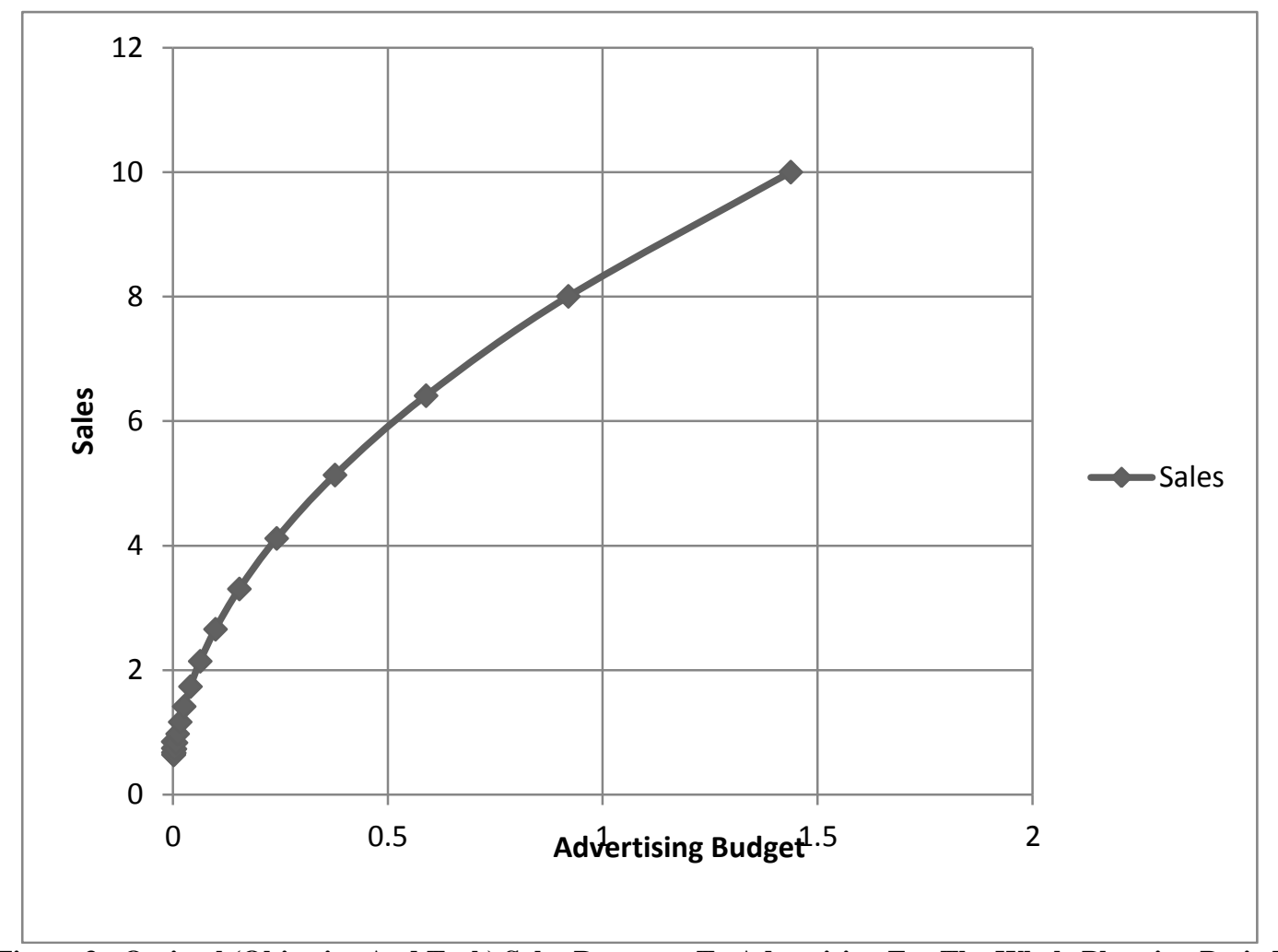

Figure 3: Optimal (Objective And Task) Sales Response To Advertising For The Whole Planning Period 


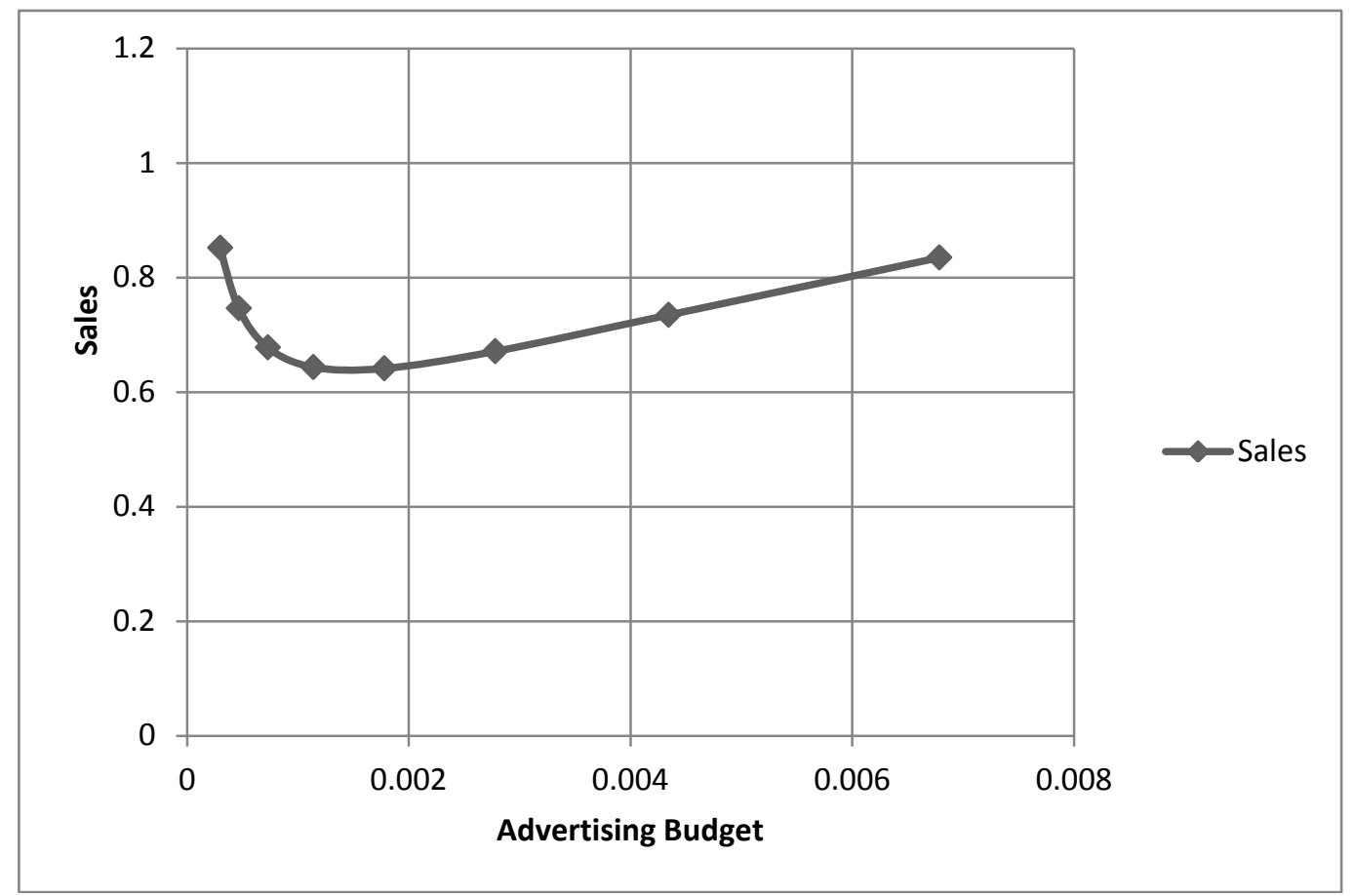

Figure 4: Optimal (Objective And Task) Sales Response To Advertising For The First Eight Periods

Based on these findings, we explain the phenomenon of thresholds in advertising effects on sales as a result of planning and optimization. In contrast, in Hibshoosh (1987) we explain this threshold, alternatively, by the stochastic character of the attitude and an attitude-behavior threshold. Our findings support two seemingly contrasting studies. Vakratas, Feinberg, Bass and Kalyanaram (2004) revealed the existence of the advertising-sales thresholds, that sales response to advertising need not be concave, and that thresholds are likely to be encountered in the dynamic environment of the earlier stages in the product life cycle. Their study is closely linked with the arguments for the S-shaped response function of Feinberg (2001) and with Mahajan and Muller's (1986) treatment of advertising pulsing strategies.

In contrast, Simon, and Arndt (1980) concluded that the advertising-sales response function, in its empirically observed section, is concave due to diminishing return. Reviewing the support for concavity and convexity in the advertising-sales response function, they conceded the existence of a convex region in the initial region of the advertising sales response function. There was some limited empirical support for this hypothesis, e.g., Rao and Miller (1975). The range of the theoretical support for a convex region was wider. It was based primarily on a functional link between the advertising and intervening psychological variables and, in turn, between those and sales, which implies the existence of thresholds. Simon and Arndt chose to focus on the following argument for convexity: At a very low advertising expenditure, the ads are too short to be considered effective. Hence, they conclude that the convex region would be a very small one and firms would choose not to operate in this convex region. A similar argument was given by Sasieni (1971) in his analytical qualification of the shape of advertisingsales response function. However, this conclusion must be understood in its context to avoid logical fallacy. Very limited advertising expenditure is sufficient for the existence of a convex section. However, it is not a necessary condition for convexity. The convex region may be wide enough to allow different levels of advertising expenditures. Hence, Simon and Arndt's conclusion of a concave response function was ultimately based on the weight of the empirical evidence.

Our simulation supports the shape conclusion of Simon and Arndt's while providing a different explanation for the convexity. In our discrete planning, the convex region does not always exist and when it does, its range is very narrow and hardly noticeable in first order statistical estimates. It may exist only if the adverting is not 
sufficiently effective (high $\alpha$ levels). Hence, the advertising-sales response function may be concave throughout its domain. Furthermore, even when the convex region exists, it is possible that the firm would decide to forgo advertising altogether in this very narrow domain (of advertising expenditures).

However, forgoing advertisement in the convex region is problematic in our model. This choice would not be optimal and the time range corresponding to the convex region is considerable. A decision not to advertise during a large part of the planning period is likely to be questionable, particularly in the context of a product in its growth stage. The firm may decide instead to overspend on advertising to the point in which sales would increase. Again, this is not an optimal behavior, though it would not increase the costs markedly. Hence, we may conjecture that under limited rationality, the firm would bypass the convex region; so our findings support Simon and Arndt's empirical conclusion of a concave response curve in the firm's operating range. However, our explanation is qualitatively different. It is based on an assumption of limited rationality rather than rationality.

Compared with other studies reviewed by Simon and Arndt, our explanation for the convex section is more a macro- than a micro-founded effect in the tradition of Jacobson and Nicosia (1981). It is the decaying effect of current consumption (approximated as sales) on future sales that leads to convexity. To see it, consider that the firm is operating at a low but sufficiently high advertising expenditure level, so that the individual advertisements are long enough to be effective. Simon and Arndt's tiny convex region is thus bypassed. The higher the advertising level, the lower is its effectiveness due to diminishing returns. This, by itself, leads to a concave advertising-sales response shape. However, at a low advertising expenditure level, the current period advertising level may not be sufficient to offset the effect of the depreciation of the preceding period sales and current period sales may decline. In the case with a relatively less effective advertisement technology, a convex section may optimally be encountered.

Also notice the optimal strategy calls for very large advertising outlays late in the planning period. This indicates the importance of later advertising outlays. Despite the marginal loss of effectiveness due to size of late outlays, their late date is beneficial as it presents benefits that last until the target date at the end of the planning period. Hence, optimization considerations, coupled with the special objective in our study, make the sales response to advertising in the end periods more concave. We propose that the pursuit of higher sales later, rather than earlier in the growth stage, together with an increasing growth margin, would lead to a trend of increasing advertising outlays toward the deadline. In turn, diminishing return of larger outlays leads to concave advertising-sales response function.

In general, the market response function of the optimal solution does not necessarily have a time period where the sales are decreasing. However, this feature of initial period with decreased sales is robust. As can be seen in Table 2, when the effect of advertising outlays on sales is slightly concave ( $\alpha=0.1$ and $\alpha=0.2$ ), sales do not decrease, even in some initial period. In contrast, in cases of a higher concavity ( $\alpha=0.4, \alpha=0.5$ and $\alpha=0.6$ ), the opposite is the case.

Furthermore, the degree and extent of decline are increasing as the concavity decreases. For $\alpha=0.4$, sales decreases only in the first quarter and only slightly, from 1 to 0.98 . In contrast, for $\alpha=0.5$ and $\alpha=0.6$, the declines continue until the fifth and seventh quarters, respectively and the declines are large, from 1 to 0.64 and 0.34 , respectively. 
Table 2: The Effect Of Sales' Response Concavity On The Optimal Solution*

\begin{tabular}{|c|c|c|c|c|c|c|c|c|c|c|}
\hline \multirow[b]{2}{*}{ Alpha Period } & \multicolumn{2}{|c|}{0.1} & \multicolumn{2}{|c|}{0.2} & \multicolumn{2}{|c|}{0.4} & \multicolumn{2}{|c|}{0.5} & \multicolumn{2}{|c|}{0.6} \\
\hline & Sales & Adv & Sales & Adv & Sales & Adv & Sales & Adv & Sales & Adv \\
\hline & & 1 & & 1 & & 1 & & 1 & & 1 \\
\hline $\mathbf{1}$ & 0.00042 & 2.179 & 0.00178 & 1.646 & 0.00093 & 0.984 & 0.00030 & 0.852 & 0.00004 & 0.807 \\
\hline 2 & 0.00054 & 3.157 & 0.00235 & 2.211 & 0.00135 & 1.000 & 0.00047 & 0.746 & 0.00008 & 0.656 \\
\hline 3 & 0.00069 & 3.975 & 0.00311 & 2.714 & 0.00196 & 1.048 & 0.00073 & 0.678 & 0.00014 & 0.539 \\
\hline 4 & 0.00089 & 4.665 & 0.00411 & 3.171 & 0.00284 & 1.125 & 0.00114 & 0.644 & 0.00024 & 0.452 \\
\hline 5 & 0.00114 & 5.255 & 0.00543 & 3.594 & 0.00411 & 1.234 & 0.00178 & 0.641 & 0.00042 & 0.390 \\
\hline 6 & 0.00146 & 5.765 & 0.00718 & 3.992 & 0.00597 & 1.374 & 0.00278 & 0.671 & 0.00073 & 0.351 \\
\hline 7 & 0.00187 & 6.212 & 0.00948 & 4.376 & 0.00866 & 1.548 & 0.00434 & 0.735 & 0.00128 & 0.336 \\
\hline 8 & 0.00239 & 6.610 & 0.01253 & 4.750 & 0.01256 & 1.759 & 0.00679 & 0.835 & 0.00223 & 0.346 \\
\hline 9 & 0.00306 & 6.970 & 0.01657 & 5.121 & 0.01821 & 2.011 & 0.01060 & 0.977 & 0.00390 & 0.384 \\
\hline 10 & 0.00392 & 7.300 & 0.02190 & 5.494 & 0.02642 & 2.310 & 0.01657 & 1.168 & 0.00681 & 0.457 \\
\hline 11 & 0.00503 & 7.607 & 0.02894 & 5.872 & 0.03832 & 2.662 & 0.02589 & 1.417 & 0.01189 & 0.576 \\
\hline 12 & 0.00644 & 7.897 & 0.03825 & 6.260 & 0.05558 & 3.074 & 0.04045 & 1.737 & 0.02077 & 0.754 \\
\hline 13 & 0.00826 & 8.175 & 0.05056 & 6.659 & 0.08061 & 3.555 & 0.06320 & 2.144 & 0.03628 & 1.014 \\
\hline 14 & 0.01058 & 8.443 & 0.06683 & 7.074 & 0.11693 & 4.115 & 0.09875 & 2.658 & 0.06339 & 1.384 \\
\hline 15 & 0.01356 & 8.706 & 0.08832 & 7.505 & 0.16960 & 4.768 & 0.15430 & 3.305 & 0.11073 & 1.908 \\
\hline 16 & 0.01737 & 8.965 & 0.11674 & 7.957 & 0.24601 & 5.526 & 0.24110 & 4.117 & 0.19344 & 2.646 \\
\hline 17 & 0.02226 & 9.223 & 0.15430 & 8.430 & 0.35684 & 6.407 & 0.37672 & 5.135 & 0.33793 & 3.682 \\
\hline 18 & 0.02852 & 9.480 & 0.20394 & 8.927 & 0.51759 & 7.431 & 0.58862 & 6.409 & 0.59033 & 5.132 \\
\hline 19 & 0.03655 & 9.739 & 0.26955 & 9.449 & 0.75076 & 8.620 & 0.91972 & 8.005 & 1.03127 & 7.162 \\
\hline 20 & 0.04683 & 10.000 & 0.35626 & 10.000 & 1.08898 & 10.000 & 1.43707 & 10.000 & 1.80155 & 10.000 \\
\hline Total Adv. & 0.21176 & & 1.45812 & & 3.50421 & & 3.99132 & & 4.21344 & \\
\hline Total Sales & & 140.323 & & 115.201 & & 70.551 & & 52.872 & & 38.976 \\
\hline
\end{tabular}

* For: $a=0.8, b=3, \alpha=0.5, \mathrm{M}=20, S_{0}=1$ and $S_{M}=20$.

In our comparison of the optimal solution, we chose to take the case where $\alpha=0.5$ for two reasons. One reason is that this case, in contrast with others, enables the derivation of explicit analytical solutions using quadratic terms and equations. It therefore eases exposition. The second, and more important, reason is that results of this model are both insightful and realistic in the case of products in the growth stage of the product life cycle. Meta analysis-based study of Sethuraman, Tellis and R. Briesch (2011) suggests a mean elasticity - roughly between 0.1 to 0.2 (.16 for the growth stage) and an elasticity range between 0 and 0.5 . However, these estimates are naturally estimates of the average elasticity of a market response function, and the study reconfirms that average elasticity varies from one stage of the product life cycle to the next. Since the sales market response is a dynamic process that depends on past sales and on past advertising outlays, a constant elasticity response, over time, is unlikely to be realistic, even though it may be a parsimonious approximation of a limit response. In our case, let us emphasize that concavity parameter $\alpha$ is not the elasticity of sales with respect to advertising and the average elasticity varies as a function of time in our model. Our model, with the parameter $\alpha=0.5$, makes this point very clear. It has an initial section of the planning period where advertising increases but sales decline. Hence, calculated elasticities, using contemporaneous advertising and sales, would be negative in this initial section. On the other hand, at the last section of a long planning period, we would expect the elasticities to increase toward the $\alpha=0.5$ value, as the size of the more recent advertising outlay exponentially increase and the effects of the initial sales virtually completely disappear. In Table 3, we demonstrate that the elasticities are monotonically increasing. They range from -0.220 in the second period to 0.444 in the final twentieth period. The average elasticity is 0.270 (or 0.259 , if estimated by the ratio of average relative sales change divided by the relative advertising change.). Hence, the average elasticity described by the reference example of our model, with $\alpha=0.5$, is not unrealistic, particularly for products in the growth stage of the product life cycle in fast expanding industries. 
Table 3: Contemporaneous Sales Advertising Elasticities*

\begin{tabular}{|c|c|c|c|c|c|}
\hline Period & Adv. & Dadv./Adv & Sales & Dsales/Sales & Elasticity \\
\hline 1 & 0.00030 & & 0.85183 & -0.14817 & \\
\hline 2 & 0.00047 & 0.56250 & 0.74625 & -0.12395 & -0.22035 \\
\hline 3 & 0.00073 & 0.56250 & 0.67798 & -0.09148 & -0.16263 \\
\hline 4 & 0.00114 & 0.56250 & 0.64361 & -0.05069 & -0.09012 \\
\hline 5 & 0.00178 & 0.56250 & 0.64142 & -0.00340 & -0.00604 \\
\hline 6 & 0.00278 & 0.56250 & 0.67131 & 0.04659 & 0.08283 \\
\hline 7 & 0.00434 & 0.56250 & 0.73476 & 0.09452 & 0.16803 \\
\hline 8 & 0.00679 & 0.56250 & 0.83494 & 0.13635 & 0.24241 \\
\hline 9 & 0.01060 & 0.56250 & 0.97688 & 0.16999 & 0.30221 \\
\hline 10 & 0.01657 & 0.56250 & 1.16766 & 0.19529 & 0.34719 \\
\hline 11 & 0.02589 & 0.56250 & 1.41682 & 0.21339 & 0.37935 \\
\hline 12 & 0.04045 & 0.56250 & 1.73682 & 0.22586 & 0.40153 \\
\hline 13 & 0.06320 & 0.56250 & 2.14366 & 0.23425 & 0.41644 \\
\hline 14 & 0.09875 & 0.56250 & 2.65768 & 0.23979 & 0.42629 \\
\hline 15 & 0.15430 & 0.56250 & 3.30459 & 0.24341 & 0.43273 \\
\hline 16 & 0.24110 & 0.56250 & 4.11673 & 0.24576 & 0.43691 \\
\hline 17 & 0.37672 & 0.56250 & 5.13471 & 0.24728 & 0.43960 \\
\hline 18 & 0.58862 & 0.56250 & 6.40942 & 0.24825 & 0.44134 \\
\hline 19 & 0.91972 & 0.56250 & 8.00460 & 0.24888 & 0.44245 \\
\hline 20 & 1.43707 & 0.56250 & 10.00001 & 0.24928 & 0.44317 \\
\hline Average & & 0.56250 & & 0.14576 & 0.27072 \\
\hline
\end{tabular}

* For: $a=0.8, b=3, \alpha=0.5, \mathrm{M}=20, S_{0}=1$ and $S_{M}=20$.

\section{CONCLUDING REMARKS AND DIRECTIONS FOR FUTURE RESEARCH}

In this paper, we characterized sales response to advertising for a firm that is effectively marketing its product in a fast-growing industry in the introduction or early growth stage. The firm's objective is to efficiently attain a minimal sales level within a pre-specified planning period. We modeled the problem as a SWC problem augmented with some alternative basic regularity conditions placed either on the sales path or on the advertising budget path.

Advertising may not be the preferred mode of promotion in many circumstances in the introductory and growth stages and its specific nature and purpose usually change as the product sales grow. However, many firms keep allocating marketing resources to advertising for the ultimate purpose of sales increase, and advertising budgets are, in practice, strongly linked with the firm's sales level and regularity conditions

We found that regardless of whether the regularity requirements are initially placed on the sales or on advertising, both corresponding paths, and thus also the sales response to advertising, exhibit regularity. We showed that the regularity conditions uniquely determine the paths and derived explicit optimal path solutions.

Our derivation of parametric explicit solutions and recursive functional relationship for optimal advertising and sales under different regularity conditions facilitate both insight into the advertising and sales processes as well as easy computation and simulation of their optimal paths.

We found that a path's regularity conditions create a mechanism that induces a degree of convexity (or concavity) on the corresponding paths and thus shapes them. In particular, the degree of this convexity for the advertising path determines the relative efficiency of its budgeting principle. The optimal advertising and sales paths of the SWC turned out to be highly convex and sets the limit on the optimal convexity.

Our finding helps explain the inconsistency in reported values of advertising elasticities and the phenomenon of thresholds in the effectiveness of advertising. We demonstrated that when the "technology" of sales production by advertising is relatively inefficient, employing the optimal advertising plan may require acceptance of sales decrease and thus negative elasticities while advertising outlays are accelerated. 
Our inquiry can be advanced in several directions. First, modeling based on combining extant mathematical extensions of the SWC, with observations drawn from marketing and business practices, would increase the range of validity of SWC-based modeling. For example, marketing adaptation of the ideas in Chen (1991) and Lee and Leitmann (1991) would enable analysis of advertising decisions for old products in their maturity stage. Likewise, incorporating various boundary conditions, commonly offered by scholars extending the SWC, would help modeling advertising budgeting under capital budgeting conditions. Second, incorporating additional selective elements of the marketing mix and their relationship would result in more comprehensive models for the introduction and growth stages of the product life cycle. These elements would include availability, price, strategic product modifications, and their relationships. Third, considering market structure effects, through embedding the SWC dynamics within a game theoretical framework, would clarify options in competitive strategy and facilitate welfare comparisons.

These extension efforts would help improve our advertising budgeting process, in particular, and advance our knowledge of the functioning of promotion as a tool of dynamic demand management in business and economics.

\section{AUTHOR INFORMATION}

Aharon Hibshoosh is a professor in the department of Marketing and Decision Sciences at the College of Business at San Jose State University. He received his PhD from the School of Business at UC Berkeley in 1974. His area of research is modeling the intersection of Marketing with Economics, Statistics and Mathematics. He also taught at UC Berkeley, CUNY's Baruch College, and The Hebrew University. He served as a consultant for major public institutions and private firms. He published in the Journal of Marketing Research, Mathematical Modeling, Decision Sciences, the International Journal of the Economics of Business, and others. E-mail: hibshoosh@gmail.com

\section{REFERENCES}

1. Buratto, A., \& Viscolani, B. (1994). An Optimal Control Student Work Problem and a Marketing Counterpart. Mathematical and Computer Modelling, 20 (6), 19-33.

2. Chen Y.H. (1991). A Revisit to the Student Learning Problem. Optimal Control Applications and Methods, 12 (4), 263-272.

3. Feinberg F.M. (2001). On Continuous-Time Optimal Advertising under S-Shaped Response. Management Science, 47 (11), 1476-1487.

4. Hibshoosh, A. (1987). Attitude Distribution Change as a Marketing Approach to Action/Sales Maximization. Mathematical Modeling, 8, 670-673.

5. Jacobson R. \& Nicosia F. M. (1981). Advertising and Public Policy: The Macro Economics Effects of Advertising. Journal of Marketing Research, 18, 29-38.

6. Klamkin, M.S. (1985). Mathematical Modeling: a Student Optimal Control Problem and Extensions. Mathematical Modeling, 6 (1), 49-64.

7. Lee C.S. \& Leitmann G.L. (1991). Some Stabilizing Study Strategies for a Student-Related Problem under Uncetainty. Dynamics and Stability of Systems, 6 (1), 63-78.

8. Low, G. S. \& Mohr, J. J. (1999). Setting Advertising and Promotion Budgets in Multi-Brand Companies. Journal of Advertising Research, 39 (1), 67-78.

9. Mahajan,V.E. \& Muller.E. (1986). Advertising Pulsing Policies for Generating awareness for New Products, Marketing Science, 52 (2), 89-106.

10. Miller, N. \& Pazgal, A.(2007). Advertising Budget in Competitive Environment. Quantitative Marketing and Economics, 5 (2), 131-161.

11. Mitchell, L. A. (1993). An Examination of Methods of Setting Advertising Budgets: Practice and the Literature., European Journal of Marketing, 27 (5), 5-22.

12. Nerlove, M. \& Arrow, K.J. (1962). Optimal Advertising Policy under Dynamic Conditions. Economica, $29,129-42$.

13. Raggett, G.F., Hempson, P.W. \& Jukes, K.A. (1981). A student related optimal control problem. Bulletin of The Institute of Mathematics and its Applications, 17, 133-136 (1981). 
14. Rao, A.G., and Miller, P.B. (1975). Advertising/Sales Response Functions. Journal of Advertising Research, 15 (2), 1-15.

15. Sasieni, M.W. (1971). Optimal Advertising expenditures. Management Science, (18), 64-72.

16. Simon J. L. \& Arndt. J. (1980). The Shape of the Advertising Response Function. Journal of Advertising Research, 20 (4), 11-28.

17. Sethuraman, R., Tellis, G.J. \& Briesch R. (2011). How Well Does Advertising Work? Generalization from a Meta-Analysis of Brand Advertising Elasticity. Forthcoming Journal of Marketing Research, Forthcoming.

18. Vakratas, D., Feinberg, F. M., Bass F. M. \&, Kalyanaram G. (2004). The Shape of Advertising Response Functions Revisited: A Model of Dynamic Probabilistic Thresholds. Marketing Science, 23 (-1), 109-119.

19. Vidalle, M. L. \& Wolfe H.B. (1957). An Operations Research Study of Sales Response to Advertising. Operations research, 5 (3), 370-381.

20. Vornicescu N. (2009). A Problem in Non Linear Optimization. Journal of Science and Art, 9 (1), 71-75.

21. Wagner, N. (2011). A Descriptive and Normative Analysis of Marketing Budgeting (Unpublished Doctoral Dissertation), University of Cologne, Germany.

22. Yoo, B. \& Mandhachitara, R. (2003). Estimating Advertising Effects of Sales in a Competitive Setting. Journal of Advertising Research, 43 (3), 310- 321. 


\section{NOTES}

